\title{
Joëlle Aden (2010), An intercultural meeting through Applied Theatre; Theaterspielen als Chance in der interkulturellen Begegnung; Rencontre interculturelle autour de pratiques théâtrales.
}

Berlin: Schibri-Verlag. ISBN 978-3-86863-053-4

\section{Mary Noonan}

This book contains a condensed account, in three languages (French, German, English) of a theatre project for adolescents that was in preparation over a two-year period, and that resulted in a week-long residential workshop for sixty young people from six partner countries at a theatre in Forbach, on the FrancoGerman border in April 2009. The initial idea for a European intercultural theatre project emerged from ANRAT, the French national association for theatre action and research, who decided to focus their efforts on young migrants in the European education system. What evolved was a project in which approximately 60 adolescents speaking 24 languages between them came together with 9 theatre practitioners from the 6 countries represented (France, Spain, Greece, Holland, Germany, the United Kingdom). The work of the group was in turn followed and observed by 5 researchers drawn from the partner countries.

The project, developed for use with young people who had recently emigrated to Europe, aimed to answer two questions:

- Can the language of theatre be used efficiently to create an intercultural dialogue?

- Can it offer a new model for intercultural exchange in both formal and informal education?

The book aims to show how these questions were answered in the course of the 'intercultural meetings' it describes. In the opening section, the author sets out the theoretical framework and the research methodology. This section is sketchy and summative, and although the author claims to be analysing theatrical activities from a new perspective - that of neurophysiology - there is nothing in this very brief theoretical outline that suggests anything more 'scientific' than that the languages of the body are multiple, and that people 
can connect with, and understand each other, without the use of words. The basic principle underpinning the work of the project seems to have been that by using exercises that involve mirroring and imitation of another's physical movements and gestures, a state of empathy can be experienced, and this in turn can facilitate integration of multiple points of view.

The conclusions drawn by the author on the basis of the workshops, questionnaires and interviews conducted with the young people in the course of the week at Forbach, are compelling. Firstly, it is clear from the work of the project that a group of young people who do not understand each other's languages can gain an impression of 'overall control' of meaning through drama work. A process of mediation was nurtured in the workshop exercises through the use of gesture, onomatopoeia, mimicry, exhibition and complicity. The use of the neutral mask and music in the workshops were also found to be highly beneficial t o the process of $\mathrm{c}$ ommunication. The practitioners found that networks of mediation developed quickly among the young people, and that through the rediscovery of the relevance of sensory perception to communication, the adolescents were able to establish, in a short period of time, confidence in themselves and in o thers. Teamwork skills were also seen to develop quickly.

To claim, however, that the theatre work developed in the context of this project is relevant to cognitive scientists who examine the relationship between speech, thought and embodied cognition may be to overstate its potential, as it is not clear - to me, at least - to what extent the project uncovered 'the mechanisms behind non-verbal and emotional understanding' (p.94). What this account does make clear, though, is that theatrical exercises carefully designed to build empathy and trust within a group, can facilitate the integration of young people newly arrived in a host-country whose language(s) they do not speak. For this reason, the present report is likely to be of interest to youth workers and educators in Europe. It presents a model that could be adapted and applied, and although the presentation of the material is unnecessarily fussy, and not always clear, the detailed description of the exercises developed by one of the groups and their two facilitators/practitioners is interesting. This section of the report could indeed be a source of ideas for other groups wishing to use theatre practice in order to develop intercultural understanding, and ultimately integration, possibly in the school system. The book directs the reader to a website offering access to footage documenting the work of this group. I failed, however, to locate this material on the given site. Such on-line resources would indeed be a valuable supplement to the present book.

Lastly, the author makes clear that there are a number of provisos, if this kind of drama work is to produce the desired results: real commitment is needed in the form of financial $r$ esources, $b$ ut a lso in t erms of acceptance of the need to involve all young people in the community - 'natives' and newly-arrived - in intercultural theatre practice. Only if there is full (financial and intellectual) commitment will it be possible for theatre workshop practice to contribute to personal and social change, based on a common understanding 
that inter-culturalism is not a question of migrant groups 'blending in' with a host culture, but of a society where all members have a constructive role to play. If there is openness to this kind of work, then drama projects such as the one described here can help young people to understand that arriving in a new country without the language of that country need not be an obstacle to succeeding within the school system and within the wider community. 